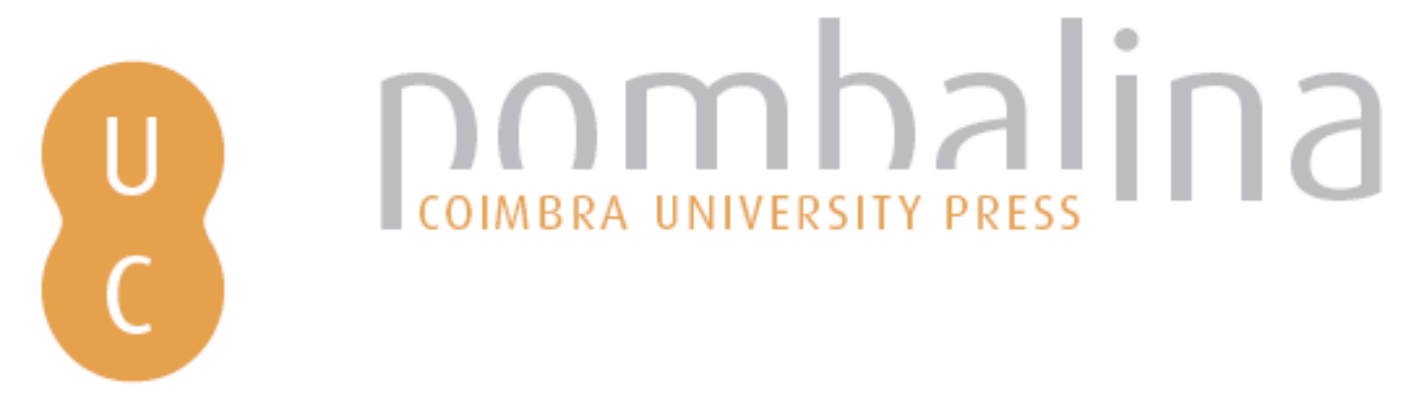

\title{
Amostragens dos solos em diferentes ambientes: litoral, serra e sertão (Ceará, Brasil)
}

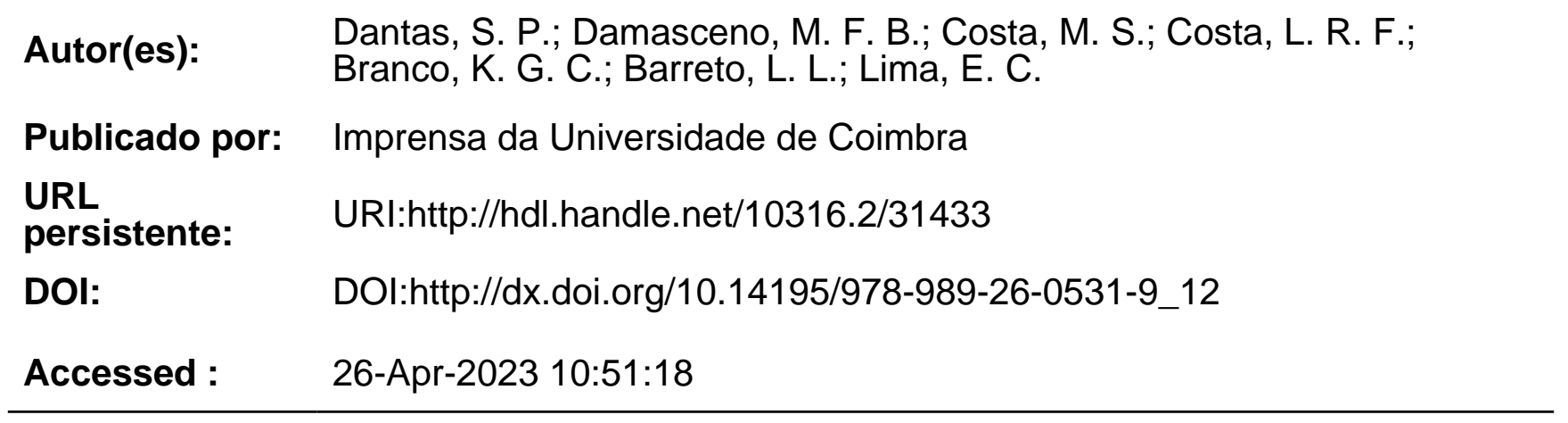

A navegação consulta e descarregamento dos títulos inseridos nas Bibliotecas Digitais UC Digitalis, UC Pombalina e UC Impactum, pressupõem a aceitação plena e sem reservas dos Termos e Condições de Uso destas Bibliotecas Digitais, disponíveis em https://digitalis.uc.pt/pt-pt/termos.

Conforme exposto nos referidos Termos e Condições de Uso, o descarregamento de títulos de acesso restrito requer uma licença válida de autorização devendo o utilizador aceder ao(s) documento(s) a partir de um endereço de IP da instituição detentora da supramencionada licença.

Ao utilizador é apenas permitido o descarregamento para uso pessoal, pelo que o emprego do(s) título(s) descarregado(s) para outro fim, designadamente comercial, carece de autorização do respetivo autor ou editor da obra.

Na medida em que todas as obras da UC Digitalis se encontram protegidas pelo Código do Direito de Autor e Direitos Conexos e demais legislação aplicável, toda a cópia, parcial ou total, deste documento, nos casos em que é legalmente admitida, deverá conter ou fazer-se acompanhar por este aviso.

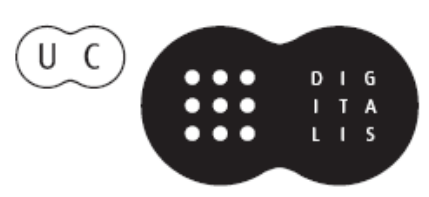





\title{
AMOSTRAGENS DOS SOLOS EM DIFERENTES AMBIENTES: LITORAL, SERRA E SERTÃO (CEARÁ, BRASIL)
}

\author{
SOIL SAMPLING IN DIFFERENT ENVIRONMENTS: \\ COAST, SERRA AND SERTÃO (CEARÁ, BRAZIL)
}

S. P. Dantas 1 , M. F. B. Damasceno ${ }^{2}$, M. S. $\operatorname{Costa}^{3}$, L. R. F. Costa ${ }^{4}$, K. G. C. Branco L. L. Barreto ${ }^{6} \&$ E. C. Lima

Resumo - Este trabalho de pesquisa foi realizado em um percurso linear em locais das cidades de Fortaleza e em Caucaia, São Luiz do Curu, Pé de Serra de Uruburetama, Amontada, Sobral, Ibiapaba (reverso), Parque Nacional de Ubajara, Tianguá e Irauçuba, correlacionando com as unidades de paisagens características de alguns trechos desses municípios. As técnicas utilizadas foram aulas teóricas, estudos laboratoriais e práticas de campo. Foram feitos levantamentos quanto às tipologias de solos recorrendo ao Sistema Brasileiro de Classificação de Solos (EMBRAPA, 1999) e, a partir disso, foram identificados solos diferenciados para cada regiáo. Com uma breve análise, concluiu-se sobre a riqueza em diversidades do solo cearense, bem como as condiçóes de uso e ocupação do mesmo.

Palavras-chave - Amostragens; Solos; Ceará; Brasil

Abstract - This research was conducted in a linear path in different places of Fortaleza and in Caucaia, São Luiz do Curu, Pé de Serra de Uruburetama, Amontada, Sobra, Ibiapaba (reverse), Ubajara National Park, Tiangua and Irauçuba, correlating with units of the landscape features of some parts of these municipalities. The techniques used include lectures and laboratory and field practices. Surveys were made regarding the type soils established in

\footnotetext{
1 Graduando em Geografia pela Universidade Federal do Ceará, Brasil; sulivandantas@yahoo.com.br

${ }^{2}$ Graduando em Geografia pela Universidade Federal do Ceará, Brasil; mariliafbd@gmail.com

${ }^{3}$ Graduando em Geografia pela Universidade Federal do Ceará, Brasil; marcelosousacosta@gmail.com

${ }^{4}$ Graduando em Geografia pela Universidade Federal do Ceará, Brasil; ricardogeoufc@yahoo.com.br

${ }^{5}$ Graduando em Geografia pela Universidade Federal do Ceará, Brasil; kaubergbranco@yahoo.com.br

${ }^{6}$ Graduando em Geografia pela Universidade Federal do Ceará, Brasil; lopes_ufc@yahoo.com.br

7 Prof. Dr. pela Universidade Estadual Vale do Acaraú, Brasil; ernanecortez@hotmail.com
} 
the Brazilian System of Soil Classification (EMBRAPA, 1999), and soil identifications were carried out for the each region. The analyses have pointed out the richness in soil diversity in Ceará, as well as the conditions of its use and occupation.

Keywords - Soil; Sampling; Ceará; Brazil

\section{1 - Introdução}

Observou-se os solos do estado do Ceará, em dez pontos que proporcionaram uma visão de diferentes situaçôes frente a variedade pedológica do nosso Estado, sendo eles: Fortaleza, Caucaia, São Luiz do Curu, Pé de Serra de Uruburetama, Amontada, Sobral, Ibiapaba (reverso), Parque Nacional de Ubajara, Tianguá e Irauçuba (Fig. 1).

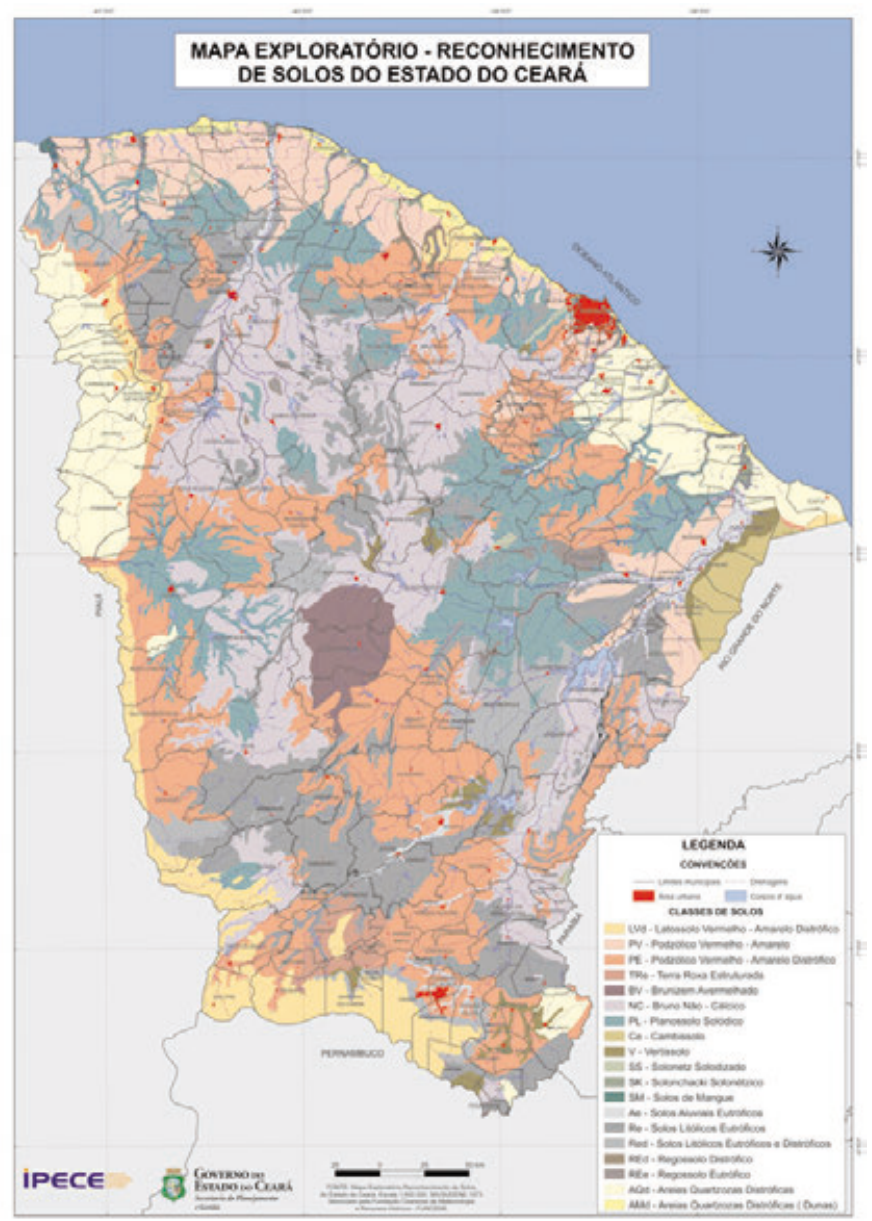

Fig. 1 - Mapa de Solos do Estado do Ceará. Fonte: IPECE (2007). 
PEREIRA \& SILVA (2007) afirmam serem

\begin{abstract}
"os solos conceituados como unidades naturais que sustentam as plantas, dotados de propriedades e características singulares, cuja origem e evolução resultam, num determinado lugar, da açáo conjugada do clima, organismos vivos, material de origem, relevo e tempo, os quais se constituem nos chamados fatores de formaçáa” (p. 123).
\end{abstract}

No campo pode-se observar através de um corte vertical exposto na superfície do terreno até o contato com a rocha subjacente, o que se denomina perfil do solo.

Neste arrazoado, o presente artigo descreve, em forma de apresentaçáo linear, os solos cearenses - que, por sua vez, são classificados de acordo com o Sistema Brasileiro de Classificação de Solos, publicado pela Empresa Brasileira de Pesquisa Agropecuária EMBRAPA, 1999 -, a saber: Latossolos vermelho-amarelos, Argissolos, vermelho-amarelos (eutróficos e distróficos), Chernossolos, Luvissolos, Planossolos, Neossolos Flúvicos, Vertissolos, Neossolos litólicos, Cambissolos, Neossolos Regolíticos, Neossolos Quartzarênicos, Gleissolos.

\title{
2 - Metodologia
}

Em geral, as técnicas para estudos de solos são realizadas em três eixos de trabalhos diferenciados; no entanto, eles se complementam. São eles: gabinete, campo e laboratório. No caso desta pesquisa, os estudos iniciaram-se com a pesquisa bibliográfica com leituras que deram subsidio para fundamentar a pesquisa; após esta fase de conceituação, utilizou-se a técnica de laboratório, mais especificamente o Laboratório de Pedologia (LAPED) da Universidade Federal do Ceará, em que foi possível observar de forma mais concreta o que se estudou.

Analisaram-se os seguintes aspectos: Cor - consiste na forma mais evidente das características morfológicas do solo, expressa a proporção dos diferentes constituintes da fase sólido do solo; relacionamos a cores vistas nas amostras de solo do laboratório com a tabela de cores MUNSELL (1994), um sistema universal que parte das cores primárias e secundárias. Os valores RGB foram convertidos para o sistema CIELAB, pelo programa Munsell Conversion 6.41 (COLORPRO, 2004).

$\mathrm{Na}$ etapa de reconhecimento e diferenciação dos elementos que compõe um solo, foi realizada a pesquisa de campo, iniciando da cidade de Fortaleza até o reverso da Cuesta da Ibiapaba, em um percurso linear de leste - oeste do Estado do Ceará, onde teríamos que descrever os solos percorridos em campo, para a escolha das paradas, onde seria pesquisado um corte do perfil, "a primeira coisa a observar é sua macro-organização, seja numa seção vertical, numa trincheira ou barranco ou nas amostras coletas com trado”. (MANFREDINI et al., 2005).

Notou-se, a cada ponto percorrido, os parâmetros morfológicos e físicos dos perfis - cor, textura, estrutura, porosidade, atividades biológicas - o que permitiu evidenciar os horizontes e relacioná-los entre si. Estabeleceu-se relação também para melhor interpretação dos perfis estudados através de mapas geológicos, pedológicos e geomorfológicos. A sistematização dos dados ocorreu da seguinte forma: aproveitar perfis já abertos, onde sua grande maioria foi à beira das estradas, após os cortes realizados com o auxílio do martelo pedológico, em perfis, foram sendo observados os elementos supracitados. 
A pesquisa iniciou-se em Fortaleza, logo após foi estudado o perfil no município de Caucaia, continuando as observaçôes houve o estudo do perfil em São Luis do Curu, em seguida o perfil do pé de serra de Uruburetama. Já o quarto perfil foi em Amontada, o quinto perfil do dia aconteceu em Sobral, o sexto perfil foi no reverso da Cuesta de Ibiapaba, a sétima foi no Parque Nacional de Ubajara, uma área de proteção ambiental, o penúltimo local de pesquisa aconteceu em Tianguá, e por fim, o último perfil de solo observado deu-se em Irauçuba.

\section{3 - Resultados e discussóes}

A pesquisa aconteceu da seguinte forma: saímos do litoral, posteriormente seguimos pela Depressáo Sertaneja, observamos algumas várzeas de rios, Maciços Residuais, e chegamos ao Planalto da Ibiapaba, encontrando assim, solos representativos para cada ambiente identificado. Abaixo há uma breve descrição dos solos encontrados ao longo da pesquisa.

Segundo a classificação do (Sistema Brasileiro de Classificação de Solos; EMBRAPA, 1999):

Argissolo vermelho-amarelo - Estes solos apresentam perfis bem diferenciados, geralmente seqüenciados por horizontes $\mathrm{A}$, Bt e $\mathrm{C}$, normalmente são profundos a muito profundos, raras são as vezes que encontram-se neles solos rasos.

Ao caracterizar este solo, pode-se perceber que o horizonte A apresenta-se de forma fraca ou moderadamente desenvolvida, outra característica é de serem por vezes abrúptico, ou seja, uma mudança textural abrupta do A para o Bt, assim como o Bt pode apresentar plintita, como foi o caso do perfil observado em pesquisa de campo. Ainda possuem coloração variada ou com mosqueado abundante, e drenagem moderada e/ou perfeita. Estes solos abrangem zonas fisiográficas do litoral, sertóes do Baixo Jaguaribe e de Baturité derivam-se dos sedimentos da formação Barreiras, e em menor proporção de arenitos da Formação Açu do Cretáceo.

No tocante ao uso atual nota-se que os solos das áreas do Litoral e sertão do Baixo Jaguaribe, restringem-se a culturas de subsistência tais como mandioca, milho, feijão e pequenos plantios de algodão herbáceo, destacam-se ainda os cajueiros na zona litorânea.

A maior limitação ao uso agrícola decorre de sua baixa fertilidade natural e forte acidez, desta forma, necessitando do uso de fertilizantes, para a correção da acidez. Um benefício é que estes são em grande parte favorecidos pelo relevo (plano e suave ondulado) que propicia boas condiçóes ao uso das máquinas agrícolas. Outro fator limitante é a baixa representatividade hídrica no período seco.

Os Neossolos Flúvicos. - No Ceará ocorrem somente solos Neossolos flúvicos eutróficos, a textura altera desde arenosa até argilosa. A espessura alterna de 10 a $26 \mathrm{~cm}$.

No que diz respeito às características químicas principais, o referido solo apresenta $\mathrm{pH}$ alternando de moderadamente ácido a moderadamente alcalino. De sorte que, estes solos são bem providos de minerais primários, no qual constitui boa fonte de nutrientes para as plantas. Ainda possuem alta fertilidade natural, também ocorrem nas várzeas dos principais rios do Estado. $\mathrm{O}$ material originário é constituído por sedimentos fluviais não consolidados de natureza e granulometria muito variada, que remontam ao Holoceno, outra característica informa-nos que o relevo é plano. 
No que se refere ao uso atual dos solos pode inferir que são intensamente aproveitados com diversas culturas, onde se destaca a cana-de-açúcar no Cariri, rizicultura, olericultura, milho, feijão, algodão, bem como fruticultura regional e extrativismo vegetal. Ao cabo que, as principais limitaçôes ao uso agrícola, procedem da falta d'água, em face das insuficientes precipitaçóes pluviométricas nas áreas semi-áridas. Os solos, por serem argilosos e imperfeitamente drenados, encharcam-se facilmente, o que provoca outras limitaçôes, além disso, estas áreas estão sujeitas a riscos de inundaçôes. Ressalta-se ainda que sob condições de clima semi-árido, a evaporação é maior que a precipitação e há tendência de acumular sais nos solos situados nas partes mais rebaixadas.

Argilossolo vermelho amarelo eutrófico - Sáo solos de média a alta fertilidade natural. O citado solo presta-nos perfis bem diferenciados, normalmente profundos, textura geralmente arenosa ou média no horizonte A, e o B é argilosa ou é média, por vezes cascalhenta, possui aspectos de solos abruptos. Geralmente, são solos bem drenados, que reflete em drenagem moderada/imperfeita, há predominância de solos moderadamente ácidos a ácidos.

No tocante, ao uso atual, em áreas próximas do litoral, os argissolos vermelho-amarelo eutrófico são utilizados com fruticultura, banana entre outras. Grosso modo, são solos com elevado potencial agrícolas, no entanto, algumas áreas apresentam problemas devido o relevo, outras limitações se refere à mecanização pela pedregosidade que há na superfície, possuem de média a alta fertilidade natural, favorecem a culturas de ciclo ou adaptadas às condiçôes de pouca umidade. Todavia, a principal limitação deste solo é a falta d'água.

Luvissolos - São moderadamente profundos a rasos, tendo sequência de horizonte no caso do corte pesquisado $\mathrm{A}, \mathrm{Bt} 1, \mathrm{Bt} 2, \mathrm{C}$, tem textura arenosa ou média no horizonte A, transiçóes planas e abruptas do horizonte A para o B. Os luvissolos cobrem grandes extensôes no Estado do Ceará, abrangendo algumas áreas do sertão Centro-Norte, sertâo central e sertão do sudeste. $\mathrm{O}$ material de origem constitui-se principalmente, por saprolito de micaxisto e gnaisses, todos eles referidos ao pré-cambriano.

Estes solos são aproveitados pela pecuária, em que é realizado de modo extensivo em meio a vegetação natural da caatinga, é importante lembrar, que este solo, tem importante relação com a caatinga. Também ocorrem pequenas culturas de subsistência, como as de milho e feijão. Como outros solos, este apresenta limitaçôes ao uso agrícola devido o déficit de água, além disso, são áreas muito susceptíveis a erosão, ao passo que são solos de alta fertilidade natural.

Neossolos Quartzarênicos - No corte do perfil observado, o referido solo apresentou a sequência dos horizontes da seguinte maneira: A, C1, C2, C3, C4+, tendo como espessura $230 \mathrm{~cm}$, não possui horizonte $\mathrm{B}$, por isso são solos pouco evoluído, é muito profundo, contudo, é jovem. Referente ao uso agrícola, estes solos são aproveitados em pequena escala, devido sua baixa fertilidade natural e a textura muito arenosa, nos últimos anos têm-se destacado a cultura do cajueiro. A limitação é a deficiência d'água, pois há uma necessidade de maior quantidade de água, uma vez que este solo é muito poroso, possui baixa fertilidade natural, são distróficos, ácidos.

Latossolo vermelho amarelo distrófico - Bem drenados a fortemente drenados, comumente bastante resistentes a erosão em decorrência da baixa mobilidade da fração argila, do alto grau de floculação e da grande porosidade e permeabilidade, são solos profundos a muito profundos, apresentando perfil: $\mathrm{O}, \mathrm{A}, \mathrm{Bw}, \mathrm{C}$. No perfil estudado nesta pesquisa os horizontes davam-se desta forma: A1, A2, Bw1, Bw2, Bw3 +, em que a diferenciação dos horizontes não era bem nítida, provavelmente tinha um horizonte $\mathrm{O}$, entretanto a área foi desmatada, não propiciando a permanência do horizonte no perfil. 
A pecuária extensiva em meio à vegetação natural constitui ainda em culturas de subsistência que são bastante freqüentes, a maior limitação ao uso agrícola deve-se a sua baixa fertilidade natural, contudo são fisicamente bons. Os latossolos vermelho-amarelos distróficos podem ser considerados, em termos de extensão, relevo e condição físicos, entre os mais importantes solos mapeados no Estado do Ceará para os futuros planejamentos agrícola, onde devem ser racionalmente e intensamente cultiváveis.

Planossolos - São solos rasos a moderadamente profundos, bem diferenciado, possuindo sequência de horizontes $\mathrm{A}, \mathrm{Bt}, \mathrm{C}$, no Ceará estes solos geralmente são de textura arenosa no horizonte A e média ou argilosa no horizonte Bt. As áreas destes solos compreendem trechos rebaixados e dissecados que acompanham os cursos d'água de regióes semi-áridas do Estado. Em sua quase totalidade, estes solos não são cultivados, situam-se em áreas com fortes limitaçóes pela falta d'água e que possuem elevado teor de sódio trocável, elevada susceptibilidade a erosão. Insere-se em extremos, sofre por excesso de água no período chuvoso e por falta de água no período seco. O uso atual é de extrativismo, na área pesquisada especificamente extrativismo de Jurema.

Ressaltamos que todas as caracterizaçóes dos solos supracitados estáo baseadas no Sistema Brasileiro de Classificação de Solos (EMBRAPA, 1999).

\section{$4-$ Conclusóes}

Conclui-se a grande riqueza que estes diferentes solos possuem, onde se relacionam com os mais variados elementos da paisagem, dando suporte de nutrientes as plantas, servindo de uso agrícola e outros fins para o homem.

É lamentável que a maioria dos solos esteja sofrendo degradação seja por desmatamento, queimadas, plantios "morro abaixo", seja pela utilização de fertilizantes e outros elementos prejudiciais ao solo, faz-se necessário nesses lugares uma maior fiscalização para o cumprimento da lei, quanto a uma conscientização - Educaçáo Ambiental para melhor utilização e conservação dos solos.

\section{Referências Bibliográfias}

COLORPRO (2004) - Munsell Conversion versão 6.41. Disponível em: http://www.colorpro.com/info/software/munsell.htm. (consultado em 2011.09.08).

EMBRAPA (1999) - Centro Nacional de Pesquisa de Solo. Sistema Brasileiro de Classificação de Solos. Rio de Janeiro, 412p.

IPECE (2007). - Ceará em Mapas. http://www2.ipece.ce.gov.br/atlas/capitulo1/12/124x.htm. (consultado em 2011.09.08).

MANFREDINI, S, DIAS, S. M. F., QUEIROZ NETO, J. P., OLIVEIRA, D. \& FERREIRA, R. O. D. (2005) Técnicas em Pedologia. In: Venturi, L. A. B. (eds.). Praticando a geografia: técnicas de campo e laboratório em geografia. São Paulo: Oficina de Textos.

MUNSELL (1994) - Munsell soil color charts. New Windsor. Rev. Ed., 10p.

PEREIRA, R. C. M. \& SILVA, E. V. (2007) - Solos e vegetação do Ceará: características gerais. In: Silva, J. B. \& Cavalgante, T. (org.). Ceará: um novo olhar geográfico. 2. ed. Fortaleza: Ediçōes Demócrito Rocha. 